\title{
Correspondence
}

\section{Anesthesia: with or without curare?}

To the Editor:

Anaphylactic reactions are a common complication of anesthesia, most often related to the use of muscle relaxants. ${ }^{1}$ The intensity varies from mild clinical manifestations to severe anaphylactic shock and death. ${ }^{2}$ With increased public awareness and the improvement in the detection and diagnosis of such adverse events, an increased frequency has been reported in most developed countries. ${ }^{3}$

In France, a recent survey estimated the incidence of anaphylactic reactions to be as high as one amongst 6,500 anesthetic procedures when a muscle relaxant is used. ${ }^{1}$ Approximately four individuals per 100 population $(2.5$ million $)$ receive muscle relaxants during anesthesia every year. ${ }^{4}$ These data allow us to postulate that among the French population alone $(60$ million people), 350 patients every year will develop a muscle relaxant mediated anaphylactic reaction. Similarly, thousands of patients all over the world will experience similar adverse events. Risk reduction requires that the use of muscle relaxants be limited inasmuch as possible since anaphylaxis may occur in patients with or without a previous history of allergy. ${ }^{1}$

To date, there are two main indications for muscle relaxants during anesthesia for elective surgery. The first involves the anesthetic procedure itself, i.e., tracheal intubation, while the second relates to the surgical procedure. Muscular relaxation facilitates airway management, access to the surgical site, closure of the abdominal wall and avoids inopportune movements. However, muscle relaxants are no longer mandatory.

There is now evidence that the development of new hypnotic drugs has changed airway management and allows tracheal intubation without the need for muscle relaxants in a selected population. ${ }^{5}$ From a surgical point of view, abdominal and thoracic procedures usually require muscular relaxation but, on the other hand, numerous peripheral surgical procedures such as lower abdominal and limb operations do not require the use of curare.

While recent data show that it is possible to intubate the trachea without resorting to muscle relaxants, the topic remains controversial. Intubating habits vary both locally and internationally. It has been suggested that muscle relaxants decrease pharyngeal and laryn- geal trauma secondary to intubation. ${ }^{5}$ As a result, several anesthesiologists are reluctant to curtail muscle relaxation for intubation. In 1996, in France, only $16 \%$ of anesthetics requiring tracheal intubation were conducted without the use of muscle relaxants. ${ }^{4}$

This puts us in a delicate situation. As anesthesiologists, we use a class of drugs, muscle relaxants, known to mediate anaphylaxis with potentially lifethreatening consequences whereas, on the other hand, there is no more doubt that we are able to avoid these drugs in many situations.

Should we still widely use muscle relaxants or should we restrict their prescription? Patient safety during anesthesia requires us to take into account all risks, even those that may have been underestimated in the past.

Christophe Baillard MD PhD

Philippe Larmignat MD

Jean Luc Fournier MD

Christophe Denantes MD

Michel Cupa MD

Charles Marc Samama MD PhD

Paris, France

\section{References}

1 Laxenaire MC, Mertes PM. Anaphylaxis during anaesthesia. Results of a two-year survey in France. $\mathrm{Br} \mathrm{J}$ Anaesth 2001; 87: 549-58.

2 Baillard C, Korinek AM, Galanton V, et al. Anaphylaxis to rocuronium. Br J Anaesth 2002; 88: 600-2.

3 Mertes PM, Laxenaire MC. Allergic reactions occurring during anaesthesia. Eur J Anaesthesiol 2002; 19: $240-62$.

4 Laxenaire MC, Auroy $\Upsilon$, Clergue F, Péquignot F, Jougla $E$, Lienhart A. Organisation et techniques de l'anesthésie. Ann Fr Anesth Réanim 1998; 17: 1317-23.

5 Conférence de consensus. Indications de la curarisation en anesthésie. Ann Fr Anesth Réanim 2000; 19: 337-472. 